\title{
Randomized controlled trials of antidepressants: clinically and scientifically irrelevant
}

\author{
David Cohen • David H. Jacobs
}

Received: 22 September 2006 / Accepted: 11 January 2007 /Published online: 1 March 2007

(C) Springer Science + Business Media, LLC 2007

\begin{abstract}
This contribution to the "antidepressant debate" focuses on the validity of randomized controlled trials (RCTs). We argue that: (a) made-up psychiatric diagnostic categories destroy the purpose and logic of the RCT as a medical experiment, (b) RCTs do everything possible to methodologically stamp out high placebo response rates rather than reveal their clinical implications, (c) assessing a psychoactive drug's effects greatly exceeds the RCT's purpose, requiring substantial investigation on normal volunteers, and (d) adverse drug reactions remain understudied, under-recognized, and underappreciated, in parallel with the muting of subjects' voice and the reliance on surrogate measures of efficacy. The standard psychopharmacotherapy RCT has lost virtually all clinical and scientific relevance, and needs complete revamping. The backdrop for the discussion is American biopsychiatry's insistence that personal difficulties must be viewed as the expression of idiopathic somatic diseases and the pharmaceutical industry's dominance of the entire drug treatment research enterprise.
\end{abstract}

Keywords randomized controlled trials .

psychopharmacotherapy · psychoactive drugs · diagnosis . placebo response - adverse drug reactions · disease model . conflicts of interest $\cdot$ pharmaceutical industry

\section{Cohen $(\bowtie)$}

School of Social Work, Florida International University, University Park Campus, HLS II 364A, Miami, FL 33199, USA

e-mail: cohenda@fiu.edu

D. H. Jacobs

Pyrysys Psychology Group, 8950 Villa La Jolla Drive,

Suite B214, La Jolla, CA 92037, USA

e-mail: David.Jacobs@pyrysys.com

\section{Introduction}

We were invited by the editors of this journal to contribute to what has been called "the antidepressant debate" [1] on the basis of a 1999 article [2] in which we endeavored to address topics receiving little attention in medical and psychiatric journals: whether psychiatric drugs' "therapeutic" effects might be more sensibly considered "toxic" [3]; how to understand the large disparities (in range, incidence, severity) between adverse drug reactions (ADRs) reported in randomized controlled trials (RCTs) and from other treatment venues; and the reluctance of the field, as a whole, to study psychiatric drugs as psychoactive drugs, that is, drugs with diverse, diffuse, and variable effects on mental life regardless of why they are used.

Our concerns and methodological suggestions, falling outside of "normal science" as it was then and is still understood, were not taken up by psychiatric drug research. Nevertheless, in the intervening years, changes from without - investigative reporting, criminal and product liability cases, whistle blowing and leaks, and the actions of regulatory bodies outside the U.S. - greatly contributed to an unmistakable crisis of confidence in all industrysponsored drug research [4]. Recently, for example, the former editor of the British Medical Journal proposed that medical journals should cease publishing all clinical trials and simply critically evaluate them for readers [5]. In psychiatric drug research, the revelatory writings of one man, David Healy, based on his access to otherwise inaccessible internal industry documents in the course of appearing as expert witness in numerous cases, greatly contributed.

In the present paper, we revisit and reformulate some of the concerns and suggestions covered in our earlier article, and we try to expand the boundaries of the usual debate by 
arguing that: (a) essentially made-up psychiatric diagnostic categories destroy the logic and purpose of the RCT as a medical experiment, (b) fully assessing a psychoactive drug's psychosocial consequences vastly exceeds the comparatively minuscule purpose of an RCT, and (c) adverse drug reactions remain understudied, under-recognized, under-reported, underappreciated, in parallel with the muting of subjects' voice and reliance on surrogate measures of efficacy. This suggests to us that the standard RCT in psychopharmacotherapy has lost virtually all clinical and scientific relevance and needs complete revamping-something easier said than done. To remind readers, standard or conventional RCTs refer to investigations with the following typical characteristics: (a) random assignment of psychiatric patients to treatment or placebo or comparison group; (b) about 6 to 8 weeks duration, (c) where the researcher is not well acquainted with the subject before the initiation of drug treatment, (d) where data on patients' clinical status and drug effects derive mainly from structured, preestablished questionnaires, (e) where data gathering on adverse effects occurs during brief, focused encounters between researcher and subject, (f) where no information about drug effects is obtained from individuals who know the subject well and are able to observe the subject in diverse and natural settings, and (g) where only data obtained while subjects are treated are considered relevant.

\section{What is treated in an antidepressant drug RCT?}

Antidepressants do not treat a specific, identifiable illness, disease, disorder, or condition called "clinical depression" or "major depressive disorder" (MDD). Such a construct is contained in the Diagnostic and Statistical Manual of Mental Disorders, Fourth edition (DSM-IV) [6], but it cannot be validated with respect to either etiopathogenesis, pathophysiology, distinctive symptomatology, course, outcome, or response to treatment. Some biological psychiatrists have regularly noted that it is pointless to aggregate a group of subjects on the basis of symptomatic diagnostic criteria and then pretend that the group so aggregated really suffers from the same condition [7, 8]. Since DSM-III, the DSM system has rested on the medically conventional principle that psychopathology can be divided into distinct categories and has postulated hundreds of autonomous disorders (although, it has also stated in its introduction that such distinctions cannot be supported empirically-but no one pays attention to this [9]). No psychiatric disorder construct began its official existence on the basis of convincing evidence of ontological reality, and it has become increasingly clear that such constructs simply do not conform to evidence [10-13]. As a scientific taxonomy, DSM is on the way out because valid case identification ("who has what disease or disorder?") has proven to be a chimera.

Careful study of the timing and appearance of clinical symptoms indicates the importance of history, context, drama, circumstances [14], yet MDD is conceptualized and presented in the DSM-IV as an endogenous, idiopathic medical illness with numerous possible guises that the physician/diagnostician must see through in order to detect the presence of a single clinical entity and unconnected to the patient's social history and current social-interpersonal situation. But "depression" as a distinct medical illness is simply made up, and so all reports of treating "it" in placebo-controlled RCTs begin by fundamentally distorting the nature of the research subject's complex and multifaceted problem. That problem involves a completely unique personal "story" and cannot be meaningfully formulated apart from it and apart from social history. The DSM's axis 4 allows the examination of social and environmental conditions, but the overall commitment to a strictly medical view of "psychiatric disorders" is such that diagnosis need not include any of these considerations. In the absence of a unique and complex story, people who "meet DSM-IV criteria for MDD" are, in effect, reduced to caricature so as to be fitted into what an RCT logically demands - that for all intents and purposes, groups of subjects are the same on factors (other than the treatment) that could influence the outcome that the trial aims to assess [15].

So, what is actually being treated in antidepressant drug RCTs? The answer is: complex cases of emotional suffering that presumably include conspicuous states of feeling depressed, despondent, dispirited, demoralized, sad, blue, betrayed, disappointed, unenergetic, apathetic, discouraged, defeated, suicidal, etc. The attempt to define or discover what depression really means as a medical-psychiatric illness proposes there is an "it" to discover-like for example the inability to produce insulin in type 1 diabetesthat is separate from language use, meaning, context, and social interaction. But, we repeat, there is simply no concept or recognition of "depressed" stripped of story, context, social expectations, norms, demands, etc. A broader, culturally diverse perspective drives this home [16]. "Depression" may be part of many medical conditions, but this does not mean that everyone who looks or feels depressed suffers from the same medical condition or that looking or feeling depressed is a symptom of any medical condition. Whether seen as a sign of a real medical disease or understood as a feature of story, it makes no sense to refer to depression as an independent illness [9]. We find it astonishing that that the idea of "major depressive disorder" as an autonomous, etiology-unknown, medical (medicalesque?) illness has the currency it has.

All that subjects in an antidepressant drug RCT share is that their emotional suffering can be described with 
expressions from the family of words that include "depression". This bears little resemblance to patients diagnosed because they share the same somatic pathology believed or known to result from the same somatic cause. For example, both in a nationwide epidemiological survey [17] and in an RCT testing fluoxetine for depression in children and adolescents [18], exactly four-fifths of subjects meeting the diagnostic criteria for MDD were also diagnosed or diagnosable with other DSM disorders, in which case, the MDD diagnosis was rarely primary. In each instance, in what way would these persons be considered to suffer from "the same disorder"?

The RCT was developed in and for medicine, but is applied in psychiatry at the cost of obscuring what is being treated, with several far-reaching consequences as we describe ahead. We have stressed that the key concept for understanding an individual's personal problems is story, not category or clinical entity. Clinicians or researchers may routinely suppress or ignore story and highlight (usually) one context-less feature, so as to conceptually create a clinical entity or category. This does not, however, render the people thus homogenized the same in the manner that the clinicians or researchers wish for and that the design of the RCT in medicine requires. If this argument has validity, then the whole point of conducting an antidepressant RCT breaks down.

\section{Neglecting the placebo response}

The RCT has become the standard test for drug manufacturers to establish the efficacy (and some of the safety) of drugs for specific DSM-IV indications. Efficacy only means demonstrating some kind of effect, or "proof in principle". Large RCTs seem used especially when an expected treatment effect is relatively small or when there is spontaneous variation in the condition being treated [19]. If a drug is clearly efficacious, it should be efficacious even in small trials, and results of efficacy should be routinely replicable. Clinical trials of selective serotonin reuptake inhibitors (SSRIs) demonstrate nowhere near this level of efficacy; at best, they show weak, marginal effects in comparison to placebo in the treatment of MDD. In other words, placebo effects are usually quite large in antidepressant RCTs, which poses a problem in the assessment of drug effects beyond placebo.

Kirsch et al. [20] reanalyzed all data obtained from the Food and Drug Administration's (FDA's) evaluations of the $47 \mathrm{RCTs}$ funded and submitted to it by the makers of the six most widely prescribed antidepressants approved by the FDA between 1987 and 1999 . The reanalysis found that $82 \%$ of the response of medicated patients was duplicated in placebo-treated patients, despite the FDA allowing the replacement of subjects on two of the drugs who were not improving after 2 weeks into the trial and the concomitant administration of benzodiazepines to patients in over half the trials (a practice that went unreported in publications of these trials). On the chief outcome measure, the Hamilton depression rating scale (HAMD), the mean difference between drug and placebo groups was a minute 1.8 points on the 50 -point or 62-point versions of the scale (a clinically insignificant but statistically significant difference).

We conducted a MEDLINE search on August 12, 2006 for past-year English-language first-time publications of double-blind, placebo-controlled randomized trials of any SSRI. This yielded seven reports of one geriatric, one pediatric, and five adult trials of five different SSRIs, conducted in three countries. Six trials involved depressed patients (one including women with breast cancer) and one looked at weight restoration in individuals diagnosed with anorexia nervosa. In no trial did the SSRI exceed placebo response on the primary endpoint. In three trials, placebotreated patients fared statistically significantly better [21-23], and in four trials, placebo and SSRI group scores did not differ statistically [24-27].

The high placebo response rates in both data sets were observed despite most studies' use of placebo-washout or placebo run-in periods, wherein all subjects are abruptly discontinued from any medications they may be taking and placed on a pill placebo, so that early placebo responders can be identified and excluded from those who will then be randomized for the study. For example, in the 47 trials reviewed by Kirsch et al. [20], any subject whose HAMD score improved $20 \%$ or more during this period was excluded from the study. As the point of all these trials is to compare the efficacy of active medication treatment to placebo treatment, it is by no means clear what the rationale could be for excluding positive placebo responders. It is also unclear whether removing early placebo responders increases drug-placebo differences at trial's end, but there is yet another issue. Because abrupt discontinuation induces a state of withdrawal [28], trials that begin with a washout "introduce a bias against the subjects who advance to the placebo arm" [29, p. 32]. In at least some subjects, these trials, in effect, compare a centrally active drug against placebo in reducing symptoms of drug withdrawal. Subjects randomized to take the drugwhich should mitigate withdrawal effects - could outperform subjects on placebo in various assessments of distress. Unfortunately, the issue is not discussed in the literature.

Also, high placebo response rates were observed despite the placebos being "inert", (e.g., flour) rather than "active" (e.g., diphenhydramine). Psychotropic drugs have certain effects, such as dry mouth or increased heart rate, which 
can serve as cues to patients and clinicians about which treatment condition they are in. One way around this problem is to use placebos without pronounced psychoactive effects but with a somewhat similar profile of "side effects" as the drug being tested. These placebos are commonly called "active placebos", and results from earlier trials showed that active placebos produced greater placebo response [30]. It was proposed that active placebos' physical effects might trick subjects into thinking that they were taking "real" medication, thus, amplifying the placebo response. Conversely, in a study using inert placebos, the truly outstanding adverse effects are likely to derive from the group on medications, which would give clinicians a cue about which treatment condition subjects are in and might tilt clinicians' observations toward amplifying the medication response. Two reviews of these earlier trials [31, 32] have not settled the matter of the precise role of inert vs active placebos, and one author suggests ignoring it altogether because the studies are dated [33]. But the issue remains relevant: if inert placebos produce equivalent or superior response in the latest available RCTs, would active placebos literally lay waste to response on "antidepressant" drugs? We cannot answer this question because we were unable to find a single RCT comparing an SSRI with an active placebo. By comparison, in neurology, RCTs of pain treatments frequently use active placebos. This void in the psychiatric literature makes no scientific sense-but is easily understandable from a political economy perspective, wherein sponsors' commercial imperatives shape the pursuit of knowledge.

Finally, it is axiomatic in clinical research that subjects' and researchers' expectations may bias their ratings, which is the reason for the double-blind RCT [15]. However, subjects might recognize their treatment because of physical characteristics of drug or placebo, desirable or adverse effects of the active drug, or cues given by the clinician [34]. As most RCTs in psychiatry are said to be doubleblind [35], knowing whether the blind is violated seems vital to interpret results. Researchers could ask patients and clinicians to guess which substance they received and estimate how much this differs from a chance guess, or reanalyze results according to patients' or observers' guesses. The FDA does not require such checks and less than one in 40 published RCTs mentions some effort to ensure blindedness [36] - a sign that editors and peer reviewers also ignore the issue.

Why the inert placebo is shown in tightly controlled trials to "benefit" (like antidepressants, by rating scale score reductions from baseline by the first week of treatment and every week thereafter) up to half of people diagnosed with MDD [37] emerges as a key question. Yet, it is obvious that the field as a whole, at least that large portion of it that is funded and controlled by the pharmaceutical industry, is less interested in answering this question than in methodologically stamping it out.

\section{Avoidance of studying psychiatric medications as psychoactive drugs}

Psychopharmacotherapy clinical trials differ greatly from the usual case in medicine, as the treatment depends on the drug being a psychoactive substance expected to alter, via its neurophysiological effects, mental and emotional life and behavior for the duration of the treatment (often suggested to last indefinitely). The drug has certain (largely unknown) effects on the central nervous system, but it is being used as a treatment in a clinical trial only because it has produced sedation, agitation, or catalepsy, etc., in earlier animal (preclinical) and normal human (phase 1) studies leading to the open trials (phase 2) and RCTs (phase 3) on diagnosed individuals. The overriding question thus becomes: What psychosocial alterations and medical consequences (neurological and others) does the regular use of a centrally active drug bring about short and long-term?

A uniform answer is impossible because the drug will not affect everyone identically. Answering the question includes distinguishing desirable from undesirable effects, identifying unambiguously adverse effects and withdrawal effects. One must ascertain the drug's psychosocial effects on normal volunteers before testing the drug with psychiatrically diagnosed individuals because multiple copresent personal difficulties confound the determination of these effects, and distinguishing between possible desirable and undesirable drug effects becomes very problematic. For example, do selective serotonin reuptake inhibitors have "antidepressant" properties or "emotional numbing" properties? [38] If the data collected during the RCT are mute on whether the drug treated group has "improved" on the basis of effects that could be construed as neuropathological (emotional muting, unconcern, euphoria, etc.), just as easily as therapeutic (decreased preoccupation with symptoms, lifting of depressed mood, etc.), then results from placebo-controlled randomized trials mean little, even if "favorable." As we suggested in our earlier article [2], RCTs are simply not designed to allow observers to make a distinction between, say, "improved mood" while on a SSRI as a return to normal from a depressed state or as a sign of drug-induced frontal lobe damage [39]. If the subject is taken seriously as a person whose distress can only be understood historically and contextually, then, on the face of it, the drug-treated person has no reason to feel less distressed except for the action of the drug itself, but its effects might not stand close examination. The RCT, again, is simply not designed to evaluate the nature of "reduced" 
distress, upset, anxiety, etc., induced by a drug. Obviously, individuals without psychiatric diagnoses must be enrolled in this effort.

The necessity to document the drug's neurological and psychosocial effects on normal volunteers before its investigatory clinical use is minimally recognized at best. Phase 1 studies conducted by pharmaceutical companies and sometimes submitted to the FDA as part of the drug approval package seem to have a shadowy existence in terms of how and why they are conducted, how data are collected, coded, and interpreted, what is actually reported to the FDA, and who has access to the original data [40]. It does seem clear that phase 1 studies are primarily conceived and conducted as toxicology studies (and sometimes as "abuse liability" studies), not as human psychoactive drug investigations - for which no established study method exists.

Nonetheless, in addition to normal volunteers, other informants who know the subject well and can observe the subject in his/her natural environment should also contribute information. The consequences of drug discontinuation, also from multiple informant perspectives, must be investigated. Finally, subjects' accounts once definitely off the drug (e.g., several months after the last dose) must be compared to their accounts under the influence (Studies with these features are actually conducted today, but only with drugs that investigators and society unambiguously label psychoactive [41]). Without such information from undiagnosed normal volunteers, diagnosed persons have no realistic basis on which to decide to be treated or not with the drug. Unfortunately, the passage of time since the publication of a famous study of dextroamphetamine effects on normal prepubertal boys [42] illustrates how little impact the demonstration had regarding assumptions of somatic pathology and "therapeutic" drug effects in the psychiatric literature on "attention-deficit/hyperactivity disorder" (ADHD).

\section{Are RCTs in psychopharmacotherapy just infomercials?}

We hope to have made it clear enough that ascertaining the full physical, psychological, and social consequences of taking a psychoactive substance daily for a long period of time constitutes a major, very complex undertaking. Standard, short-term psychopharmacotherapy RCTs are not designed for this undertaking, but for the much narrower purpose of showing treatment superiority of one drug over inert placebo or non-inferiority to another drug used to treat the same condition. This is precisely why RCTs have little relevance to clinical practice. In practice, antidepressants are prescribed to very severe cases, very mild cases, pregnant women, frail older people, illiterates, people who would never accept to take a placebo-all cases that are excluded from the vast majority of RCTs [43]. In practice, drugs can be prescribed for months and years, not the average 6- to 8-week duration of the RCT. In practice, the majority of people treated with an SSRI have multiple symptoms and are prescribed more than one psychoactive drug simultaneously [44]. The effort made in RCTs to exclude many people who will actually be exposed to the drug in clinical practice and to limit exposure to one indicated disorder opens an unbridgeable gap between research and practice.

In both research studies and in clinical practice, that so many suffering people treated with "safe and effective" medications soon decline to continue taking them (e.g., $42 \%$ of adults who initiated antidepressants between 1996 and 2001 discontinued them within 1 month, and only $28 \%$ continued beyond 3 months [45]) invokes only laments of noncompliance on the part of most psychiatrists [46]. In medicine, it may be that clinicians usually know that the burden of the treatment is less than the burden of the disease in the long run, even if the patient does not know this. But in psychiatry, course, outcome, and response to treatment vary in the extreme. People treated with antidepressants may fare worse in the long run than people not treated [47]. The burden of the drug may be severe and long lasting, while the severity of the condition may be mild and transitory. This reality is continually obscured by "disease mongering", meaning the relentless expansion of defining human distress in all its guises and at all levels of severity as "diseases" requiring drug treatment (see PLoS Medicine, volume 3, issue 4, 2006, featuring six essays on the topic).

Mostly, the drug treatment literature ignores the existence of psychotherapy. Psychotherapy research itself has been distorted to compete with the supposed rapid efficacy of drug treatment [48]. Exposure to centrally active drugs, even for a long time, is usually regarded as the first and only option-drugs are compared to inert placebo or to other drugs (how fairly one drug is compared to another depends a great deal on who is paying for the study [49]). Such is the commitment to regarding personal difficulties in the emotional realm as the socially visible signs of an endogenous, idiopathic somatic disease that requires drug treatment that "...life style modifications, which is widely practiced [in medicine] for the prevention of relapse [in various real somatic diseases] is not even considered in clinical psychiatry...” [50], p. 129].

In summary, the typical psychopharmacotherapy clinical trial might reasonably qualify as an infomercial: a communication aimed to promote a product in a supposedly objective manner, but actually divorced from reality. In the typical infomercial, the product performs well during 
impractical tests, its defects and disadvantages are not hinted at, and the approving observers were bought.

\section{Adverse drug reactions: understudied, under-recognized, under-reported, underappreciated}

We noted in our earlier paper [2] that serious ADRs are rarely, if ever, reported in published RCTs, in contrast to an unending stream of reports of serious ADRs appearing in psychiatry journals based on open trials, retrospective chart reviews, and observations made in clinical practice. With respect to SSRIs, the list includes delayed orgasm/ejaculation and anorgasmia [51-53], suicidal ideation [54], lethargic/apathetic frontal lobe syndrome [39, 55], growth suppression [56], hostility, aggression, and violence [57, 58], withdrawal reactions [27], and various forms of behavioral toxicity [59]. We conjectured that this obvious and glaring disparity (if one elects to notice it) probably could be understood, at least in part, on the basis of sponsorship and the resultant bias that sponsorship creates.

By waiting for patients to complain about a drug effect, or by asking about unpleasant effects in open-ended questions - rather than by systematically eliciting reports from patients and extending the observation period - rates of side-effects usually appear to be substantially low [60]. In outpatient trials, subjects are typically evaluated once a week or less often, during relatively brief encounters with clinicians who do not know them. In the first 11 published reports of ADHD trials of atomoxetine, ten reports described their methods for eliciting adverse effect information in no more than the following: "open-ended questioning", "unsolicited reports", "self-report", "spontaneous report from parent or child", or no methodology. The criteria for reporting the adverse effects in the publication varied even more: "reported in at least $5 \%$ of patients in any treatment group," "occurring in $>10 \%$ of treatment group", "most frequent", "most common", "reported in at least 5\% of treatment group and statistically significantly more frequent than placebo", or no criteria [61]. Such derisory methods underscore the irrationality of overemphasizing the validity of the "causal" standard or conventional placebo-controlled trial design in detecting "true" adverse effects, or conversely, of systematically questioning the drug-induced status of effects observed in routine clinical practice or reported in "merely anecdotal" or "uncontrolled" case studies (On the other hand, even unmistakable effects emerging in the "causal" placebo-controlled RCT, such as double the rate of suicidal ideation in depressed youths treated with antidepressants [54], can also be intensely questioned - but, seemingly, only if they disturb the relentlessly promoted portrait of the drugs as "safe and effective").
Another source for the disparity between RCT and other treatment venue reports of adverse drug effects may be widespread polypharmacy in ordinary clinical practice. For example, based on challenge-dechallenge for 533 consecutive inpatient admissions over a 14-month period, an $8.1 \%$ rate of antidepressant-induced psychosis or mania was observed [62]. Assessment (such as it is) of a drug's adverse effects in an RCT is a poor guide to what will occur when the same drug is combined with other psychoactive drugs. Indeed, among these inpatient admissions, polypharmacy was the rule. Many, if not most, of these patients would have been excluded from an antidepressant RCT because they were taking multiple drugs. However, patients deliberately excluded from RCTs are nonetheless prescribed, in clinical practice, the same drug that cannot be studied on them-along with other drugs-for the same indication or other indications. Thus, RCTs may simply miss noticing adverse effects that frequently happen under more realistic treatment circumstances. Of note, the authors of the report convey a message of rapid remission of mania or psychosis once dechallenge of the antidepressant was instituted and other drugs were substituted.The three clinical examples provided in the text all have rapid happy endings, but no follow-up is described. We did not detect any interest in the impact on the patient, from the patient's own perspective, of antidepressant-induced psychosis or mania severe enough to require hospitalization. Indeed, we are unaware of any report on ADRs, regardless of severity and incidence, published in a psychiatry journal, that suggests more than "increased vigilance" on the part of prescribers. But it is uncertain what increased vigilance should mean or what it can accomplish in clinical practice. It is widely recognized that only a minuscule fraction of ADRs are reported to the professional literature or to regulatory bodies [63], so it is probably safe to conclude that professional estimates of an antidepressant's "safety in use" (an FDA expression) represent a gross underestimation.

Medawar and Herxheimer [64, p. 167] compared two sources of accounts of antidepressant adverse effects: firstperson accounts sent by patients to Social Audit, and "Yellow Card" reports sent in by physicians to the U.K.'s Committee on Safety of Medicine (CSM). Different portraits of drug safety emerged from these different sources. "[Yellow Card reports] are mainly written in doctors' own words, usually a translation into medical shorthand of what the patient says. This often entails some misunderstanding or misinterpretation [on the part of CSM coders] and inevitably omits much detail, especially the personal and social consequences of unwanted drug effects. These e-mails [sent to Social Audit] recorded major problems for relationships, employment, and locomotion (e.g., driving)." 


\section{The research subject's muted, absent, or interpreted voice}

If the only way to realistically depict the subject or patient's "personal difficulties" (DSM-IV's axis 4 uses this expression) is in terms of a unique story that includes history and dramatis personae, then it is unrealistic to become too committed - in advance of hearing the story and awaiting further developments - to a fixed idea or measure of a happy ending (i.e., therapeutic gain, progress, benefit), such as a $50 \%$ reduction in baseline score of a rating scale. This is by way of asserting that bringing a relevant "clinical" story into existence (a story that addresses "what's the matter?" with this person) and addendums to the story (which address how the person is doing now after $x$ amount of treatment) must honor that there is no single official version of the story. Certainly, the patient's own version cannot be ignored. But in the conventional medical framework of psychiatric drug treatment research, the patient's own voice is either eliminated or relegated to a distinctly inferior position. The subject in an RCT is first rendered a "serviceable other" (or caricature) with regard to "what's the matter" to be fitted into the RCT's requirement of "disorder homogeneity", then rendered mute or irrelevant about how he or she is doing during and at the conclusion of treatment. That is, the treating psychiatrist-researcher speaks for the research subject both with regard to clinical status and unwanted drug effects (by structuring the research subject's speaking/ reporting opportunities and by interpreting and "translating" what the research subject does say).

The taken-for-granted "necessity" for the psychiatristresearcher to authoritatively interpret what the subject says and how the subject appears and to present the interpretation as the "primary" outcome seems so compelling that it is rarely discussed. Why a disparity routinely exists between the researcher-interpreted version of the treatment outcome and the subjects' own version-albeit limited by the instruments the researcher provides [65, 66]-also remains usually undiscussed. From start to finish of an antidepressant RCT, the subject's or patient's own views of personal troubles and treatment effects are regarded in the usual medical fashion, that is, as possibly useful information to be expertly evaluated [67]. But in psychiatry, little objective scientific knowledge can be brought to bear on how the patient looks, behaves, and what he or she says, so one cannot confidently regard the patient's own view of his or her status at the conclusion of treatment as expendable. In familiar medical treatment research parlance, this renders the preferred or exclusive reliance on the psychiatrist'sresearcher's evaluations tantamount to a "surrogate" outcome indicator.

In previous sections, we have made some suggestions regarding more realistic study of drugs thought or hoped to exert an antidepressant effect. We have emphasized, in this section, that the patient's own voice is muted or absent both with regard to what is the problem and with regard to the pros and cons of treatment. A main reason for quantification of the patient's views is to analyze group scores statistically, as the patient will not naturally use numbers when trying to convey his or her impressions. The researcher creates numerical scores to represent the patient's problem at the start of treatment, during treatment, at the end of treatment, and also lists side effects in terms of presence or absence (rarely, of intensity), all for the purpose of statistical analysis. The extent to which it is reasonable to represent psychological matters numerically is, of course, a critical topic in the history of psychology as a research field. Probably, few would suggest that nothing of importance is lost in the numerous translations of the patient's attempt to convey information through discourse into numbers, and criticisms of conventional drug treatment methodology and findings frequently amount to presenting information narratively which is held to have been lost or overlooked or buried by its transformation into scores on one or more scales. It may be tedious to solicit narratives from research subjects and to present what the subjects actually said in the ultimate report to the various interested parties, and it may be time-consuming for readers to examine what patients actually said or to examine even summaries of their discourse. Nevertheless, the patient's voice is lost in the usual approach to collecting and analyzing data. We believe it sensible that ethnological drug treatment studies be recognized as a critical component of the overall drug treatment research enterprise so that the voice of the patient is not lost from what is "known" about drug treatment safety and efficacy.

\section{The current status of scientific research, government protection of the public, and expert medical opinion}

In every section above, we omitted a focused discussion of conflicts of interest and the industry's dominance of psychiatric drug treatment research, as a whole, although this forms the backdrop for every topic addressed so far [4, 68-72]. Because the RCT constitutes the principal hurdle that drug manufacturers must pass to have their products approved for marketing, they need, in the USA, to only produce two RCTs showing their drug's superiority to placebo and/or equivalence to an existing drug for the same indication to generate potentially astronomical profits. This means that the design, conduct, analysis, and publication of clinical trials are marketing issues for drug manufacturers [73]. Unquestionably, the very purposes of these oncepresumably scientific activities are (for the bulk of clinical trials today) to gain FDA approval of a drug and then to 
alter physicians' prescribing behavior to increase the drug's market share [74]. Recognition of this fact has recently led to what is regularly called "a crisis in the perceived integrity of all clinical trials", notably those involving the SSRIs [4, 75-78]. In contrast with the rest of medicine, however, only belatedly has the extent of the crisis begun to be publicly acknowledged in psychiatric journals [35, 79].

Here follows, in dense form, a brief overview of the topography, focusing on the SSRIs, and how different social actors contribute to it and are caught in it. All the members of the DSM-IV and DSM-IV-TR panels on "mood disorders" and "schizophrenia and other psychotic disorders" had financial ties to drug companies [80]. More than half of the members of the FDA's 18 expert advisory panels had a direct financial interest in the drug or topic about which they advised the FDA [81]. The FDA forbids its own researcher from publishing findings on the risk of suicidal ideation in children taking SSRIs [82], and the FDA's own lead counsel attempted to annul a federal judge's order that the makers of paroxetine stop making the misleading advertisement claim that "Paxil is not habit forming" [83]. Medical schools in the U.S. routinely engage in industrysponsored research that fails to adhere to the International Committee of Medical Journal Editors' standards regarding clinical trial design, access to data, and publication rights [84]. When asked about certain serious adverse effects in his two fluoxetine pediatric trials (one of which was funded by a public agency and both of which were already published), the lead academic investigator "declined to disclose what he knew, invoking secrecy contracts he signed with a pharmaceutical company" [85].

Pharmaceutical companies or their subcontractors enlist academics to form expert panels to construct guidelines and algorithms that assert or argue that newer, more expensive drugs (SSRIs and atypical antipsychotics) are more effective and must become first-line treatments, in the absence of definitive data or the presence of contradictory data [86]; in some states, such algorithms are promoted by means of covert, illicit cash payments to state officials responsible to make the drugs eligible for government funding [87]. Professional writers are hired to pen articles of RCTs or literature reviews, on which prominent academic names appear who might have never seen, let alone analyzed, the raw data [74, 88-90]. These articles have wider impact on the field than articles on the same topics that are independently written [91]. When the editor of the New England Journal of Medicine sought a research psychiatrist with no ties to the drug industry to evaluate an SSRI trial, she could find none [92]. When the American Journal of Psychiatry published a pediatric RCT of citalopram which reported positive results, neither the authors nor the editors disclosed (or knew) that a previous unpublished pediatric RCT funded by the same sponsor had observed opposite results $[93,94]$. When an article in $J A M A$ warned pregnant women not to stop antidepressants because of the risk of reexperiencing depression, most of the 13 authors did not disclose their financial ties to makers of antidepressants [95]. When all 42 RCTs of five SSRIs submitted to the Swedish drug regulatory authority as a basis for marketing approval (and unavailable to practitioners) were compared with the reports from these RCTs actually published in the literature, researchers found evidence of multiple publication, selective publication, and selective reporting [96].

A research group on adverse drug events reported, without intentional irony, that "the legal system is becoming an increasingly important participant in postmarketing safety assessments" because lawsuits against manufacturers enable expert witnesses to access company documents that are not normally available to anyone, and although unpublished clinical trials and safety reports from industry would greatly facilitate identifying ADRs, "these data are not easily obtained" [97]. Drug companies routinely fail to carry out postmarketing safety (phase 4) studies required by the FDA [98]. "[O]nly half of newly discovered serious ADRs are detected and documented in the [Physician's Desk Reference] within 7 years of drug approval" [97]. The direct patient ADR reporting system created in the Netherlands identified nine new ADRs for paroxetine about 273 days before the same ADRs were identified by the Netherlands Pharmacovigilance Foundation based on physician reports [99]. Since the 1992 adoption in the U.S. of the Prescription Drug User Fee Act (i.e., drug manufacturers seeking product approval from the FDA directly pay the FDA), median approval times for nonpriority drugs decreased from 27 months in 1993 to 14 months in 2001, but as "an inevitable consequence" drug recalls increased from $1.6 \%$ for $1993-1996$ to $5.3 \%$ in 2001 [81].

\section{Conclusion: whither drug research?}

American biopsychiatry or neo-Kraepelinism has postulated for the past 30 years that the entire spectrum of "clinically significant" human misery and/or psychosocial deviance is "really" based on endogenous biological faults, and it has enlisted (or become a satellite branch of) the multinational drug industry to promote its postulate. The industry is itself increasingly oblivious to the scientific relevance of its activities as long as they remain profitable and is only too eager to spend whatever is necessary to maintain the alliance intact [100]. It is difficult to imagine how the psychiatric drug research industry will change from within, as long as no actor is pressed to account for the failure to deliver on promises (i.e., to find the twisted molecule behind every twisted thought and to provide safe and effective treatments). 
Of course, changes from without are unceasing and powerful, but there is no obvious indication of where the field is headed. Two related trends are apparent: the increasing irrelevance of medical experts and medical intermediaries (encouraged by direct-to-consumer advertising of pharmaceuticals) and the construction of knowledge about psychotropic drugs moving completely beyond the traditional confines of medical research (made possible by the Internet and its ability to give direct, uninterpreted voice to laypersons) [101]. The implications of these two developments are far from clear. But for our part, we suggest that the entire drugs-as-first-line-treatment-forpersonal-problems research enterprise has turned a blind eye to two fundamental principles: (a) "In approaching [the issue of exposure to chemicals and toxicity] it is indeed instructive to take as a starting point the extreme position: that the effects of chemicals on organisms are mostly bad" [102]; (b) "Like all psychotropic agents, the behavioral and neuropharmacological effects of fluoxetine are complex and variable" [103, our italics].

\section{References}

1. Moncrieff J (2002) The antidepressant debate. Br J Psychiatry 180:193-194

2. Jacobs D, Cohen D (1999) What is really known about psychological alterations produced by psychiatric drugs? Int J Risk Saf Med 12:37-47

3. Breggin PR (1997) Brain disabling treatments in psychiatry. Springer Publishing, New York

4. Medawar C, Hardon A (2004) Medicines out of control? Antidepressants and the conspiracy of goodwill. Aksant Academic Publishers/Transaction, London

5. Smith R (2005) Medical journals are an extension of the marketing arm of pharmaceutical companies. PLoS Med 2(5): e138

6. American Psychiatric Association (1994) Diagnostic and statistical manual of mental disorders, 4th ed. American Psychiatric Press, Washington DC

7. van Praag HM (1998) The diagnosis of depression in disorder. Aust N Z J Psychiatry 32:767-772

8. van Praag HM (2000) Nosologomania: a disorder of psychiatry. World J Biol Psychiatry 1:151-158

9. Jacobs DH, Cohen D (2003) Hidden in plain sight: DSM-IV's rejection of the categorical approach to diagnosis. Rev Existent Psychol Psychiatry 26

10. Caine ED (2003) Determining causation in psychiatry. In: Phillips KA, First MB, Pincus HA (eds) Advancing DSM: dilemmas in psychiatric diagnosis. American Psychiatric Press, Washington, DC, pp1-22

11. Hyman SE (2003) Forward. In: Phillips KA, First MB, Pincus HA (eds) Advancing DSM: dilemmas in psychiatric diagnosis. American Psychiatric Press, Washington, DC, ppxi-xxi

12. Merikangas KR (2003) Will the genomic revolution revolutionize psychiatry? Am J Psychiatry 160:625-635

13. Widiger TA, Thomas A, Coker LA (2003) Mental disorders as discrete clinical conditions: dimensional vs. categorical classification. In: Hersen M, Turner SM (eds) Adult psychopathology and diagnosis. Wiley, New York, pp3-34
14. Leff MJ, Roatch JF, Bunney Jr, WE (1970) Environmental factors preceding the onset of severe depression. Psychiatry 33:293-311

15. Elwood M (1998) Critical appraisal of epidemiological studies and clinical trials, (2nd edn.) Oxford University Press, Oxford

16. Mezzich JE, Kirmayer LJ, Kleinman A et al (1999) The place of culture in DSM-IV. J Nerv Ment Dis 187:457-464

17. Kessler RC, Berglund P, Demler O et al (2003) The epidemiology of major depression: results from the National Comorbidity Survey Replication (NCS-R). JAMA 289:3095-3105

18. Emslie GJ, Rush J, Weinberg WA et al (1997) A double-blind, randomized, placebo-controlled trial of fluoxetine in children and adolescents with depression. Arch Gen Psychiatry 54:10311037

19. Healy D, Langmaak C, Savage M (1999) Suicide in the course of the treatment of depression. J Psychopharmacol 13:94-99

20. Kirsch I, Moore TJ, Scoboria A et al (2002) The Emperor's new drugs: an analysis of antidepressant medication data submitted to the U.S. Food and Drug Administration. Prev Treat. 5: article 23. Available: http://journals.apa.org/prevention/volume5/toc-jul1502.htm

21. Moreno RA, Teng CT, Almeida KM et al (2006) Hypericum perforatum versus fluoxetine in the treatment of mild to moderate depression: a randomized double-blind trial in a Brazilian sample. Rev Bras Psiquiatr 28(1):29-32

22. Musselman DL, Somerset WI, Guo Y et al (2006) A doubleblind, multicenter, parallel-group study of paroxetine, desipramine, or placebo in breast cancer patients (stages I, II, III, and IV) with major depression. J Clin Psychiatry 67:288-296

23. Schatzberg A, Roose S (2006) A double-blind, placebocontrolled study of venlafaxine and fluoxetine in geriatric outpatients with major depression. Am J Geriatr Psychiatry 14:361-370

24. Fava M, Alpert J, Nierenberg AA et al (2005) A double-blind, randomized trial of St John's wort, fluoxetine, and placebo in major depressive disorder. J Clin Psychopharmacol 25:441-447

25. Gastpar M, Singer A, Zellek K (2006) Comparative efficacy and safety of a once-daily dosage of hypericum extract STW3-VI and citalopram in patients with moderate depression: a double-blind, randomised, multi-centre, placebo-controlled study. Pharmacopsychiatry 39(2):66-75

26. Wagner KD, Jonas J, Findling RL et al (2006) A double-blind, randomized, placebo-controlled trial of escitalopram in the treatment of pediatric depression. J Am Acad Child Adolesc Psych 45:280-288

27. Walsh BT, Kaplan AS, Attia E et al (2006) Fluoxetine after weight restoration in anorexia nervosa: a randomized controlled trial. JAMA 295(22):2605-2612

28. Warner CH, Bobo W, Warner C et al (2006) Antidepressant discontinuation syndrome. Am Fam Phys 74:449-456

29. Jackson GE (2005) Rethinking psychiatric drugs: a guide for informed consent. AuthorHouse, Blomington, Indiana

30. Fisher S, Greenberg RG (1993) How sound is the double-blind design for evaluating psychotropic drugs? J Nerv Ment Dis 181:345-350

31. Moncrieff J, Wessely S, Hardy R (2004) Active placebos versus antidepressants for depression. Cochrane Database Syst Rev 1: CD003012

32. Petovka E, Quitkin FM, McGrath PJ et al (2000) A method to quantify rater bias in antidepressant trials. Neuropsychopharmacol 22:559-565

33. Quitkin FM (2003) Reply to "Active placebos versus antidepressants for depression" by Moncrieff J, Wessely S, and Hardy $\mathrm{R}$ in The Cochrane Database of Systematic Reviews, 2002. Retrieved 27 June 2006 from: http://www.cochranefeedback. $\mathrm{com} / \mathrm{cf} / \mathrm{cda} / \mathrm{citation} . \mathrm{do}$ ?id=9048\#9048 
34. Desbiens NA (2002) In randomized controlled trials, should subjects in both placebo and drug groups be expected to guess that they are taking drug 50\% of the time? Med Hyp 59:227-232

35. Perlis RH, Perlis CS, Wu Y et al (2005) Industry sponsorship and financial conflict of interest in the reporting of clinical trials in psychiatry. Am J Psychiatry 162:1957-1960

36. Even C, Siobud-Dorocant E, Dardennes RM (2000) Critical approach to antidepressant trials: blindness protection is necessary, feasible and measurable. Br J Psychiatry 177:47-51

37. Walsh BT, Seidman SN, Sysko R et al (2002) Placebo response in studies of major depression: variable, substantial, and growing. JAMA 287:1840-1847

38. Moncrieff J, Cohen D (2006) Do antidepressants cure or create abnormal brain states? PLoS Med 3(7):e240

39. Hoehn-Saric R, Lipsey JR, McLeod DA (1990) Apathy and indifference in patients on fluvoxamine and fluoxetine. J Clin Psychopharmacol 10:343-345

40. Healy D (2004) Let them eat Prozac: the unhealthy relationship between the pharmaceutical industry and depression. New York University Press, New York

41. Griffiths RR, Richards WA, McCann U et al (2006) Psylocybin can occasion mystical-type experiences having substantial and sustained personal meaning and spiritual significance. Psychopharmacol (Berl) 187:268-283

42. Rapoport J, Buchsbaum MS, Zahn TP et al (1978) Dextroamphetamine: cognitive and behavioral effects in normal prepubertal boys. Science 199(4328):560-563

43. Seeman MV (2001) Clinical trials in psychiatry: do results apply to practice? Can J Psychiatry 46:352-355

44. Silkey B, Preskorn SH, Golbeck A et al (2005) Complexity of medication use in the Veterans Affairs healthcare system: part II. Antidepressant use among younger and older outpatients. J Psychiatr Pract 11:16-26

45. Olfson M, Marcus SC, Tedeschi M et al (2006) Continuity of antidepressant treatment for adults with depression in the United States. Am J Psychiatry 163:101-108

46. Mitchell AJ (2006) High medication discontinuation rates in psychiatry: how often is it understandable? J Clin Psychopharmacol 26:109-112

47. Moncrieff J, Kirsch I (2006) Efficacy of antidepressants in adults. BMJ 331:155-159

48. Weston D, Novotny CM, Thompson-Brenner H (2004) The empirical status of empirically supported psychotherapies: Assumptions, findings, and reporting in controlled clinical trials. Psychol Bull 130:631-663

49. Heres S, Davis J, Maino K et al (2006) Why olanzapine beats risperidone, risperidone beats quetiapine, and quetiapine beats olanzapine: an exploratory analysis of head-to-head comparison studies of second-generation antipsychotics. Am J Psychiatry 163:185-194

50. Fava GA (2002) Long-term treatment with antidepressant drugs: the spectacular achievements of propaganda. Psychother Psychosom 71:127-132

51. Stimmel GL, Gutierrez MA (2006) Sexual dysfunction and psychotropic medication. CNS Spectr 11(8 Suppl 9):24-30

52. Landen M, Hogberg P, Thase ME (2005) Incidence of sexual side effects in refractory depression during treatment with citalopram or paroxetine. J Clin Psychiatry 66:100-106

53. Csoka AB, Shipko S (2006) Persistent sexual side effects after SSRI discontinuation. Psychother Psychosom 75:187-188

54. Mosholder AD, Willy M (2006) Suicidal adverse events in pediatric randomized controlled trials of antidepressant drugs are associated with active drug treatment: a meta-analysis. J Child Adolesc Psychopharmacol 16:25-32

55. Garland EJ, Baerg EA (2001) Amotivational syndrome associated with selective serotonin reuptake inhibitors in children and adolescents. J Child Adolesc Psychopharmacol $11: 181-186$

56. Weintrob N, Cohen D, Klipper-Aurbach Y et al (2002) Decreased growth during therapy with selective serotonin reuptake inhibitors. Arch Pediatr Adolesc Med 156:696-701

57. Jain B, Birmaher M, Garcia M et al (1992) Fluoxetine in child and adolescents with mood disorders: a chart review of efficacy and adverse reactions. J Child Adolesc Psychopharmacol 2:259-265

58. Healy D, Herxheimer A, Minkes DB (2006) Antidepressants and violence: problems at the interface of medicine and law. PLoS Med 3(9):e372

59. Wilens TE, Biederman J, Timothy E et al (2003) Systematic chart review of the nature of psychiatric adverse events in children and adolescents treated with selective serotonin reuptake inhibitors. J Child Adolesc Psychopharmacol 13:143-152

60. Safer DJ (2002) Design and reporting modifications in industrysponsored comparative psychopharmacology trials. J Nerv Ment Dis 190:583-592

61. Cohen D (2004) Critical review of clinical trials of atomoxetine. 31st Annual Pediatric for Practicing Physician, Medical College of Ohio, 31 May

62. Preda A, MacLean RW, Mazure CM et al (2001) Antidepressantassociated mania and psychosis resulting in psychiatric admissions. J Clin Psychiatry 62:30-33

63. Lexchin $J$ (2006) Is there still a role for spontaneous reporting of adverse drug reactions? CMAJ 174:191-192

64. Medawar C, Herxheimer A (2003/2004) A comparison of adverse drug reaction reports from professionals and users, relating to risk of dependence and suicidal behavior from paroxetine. Int J Risk Saf Med 16:5-19

65. Lasalvia A, Ruggeri M, Santolini N (2002) Subjective quality of life: its relationship with clinician-rated and patient-rated psychopathology. The South-Verona Outcome Project 6. Psychother Psychosom 71:275-284

66. Healy D (2003, June 20) Antidepressants and suicide briefing paper, p. 37 Retrieved August 1, 2006 from http://www. socialaudit.org.uk/58090-DH-htm

67. McHugh PR, Slavney P (1998) The perspectives of psychiatry, (2nd edn). Johns Hopkins University Press, Baltimore

68. Abramson J (2004) Overdo\$ed America: the broken promise of American medicine. HarperCollins, New York

69. Angell MB (2004) The truth about drug companies: how they deceive us and what to do about it. Random House, New York

70. Cohen D (2005) Clinical trials in psychopharmacology: "gold standard" or fool's gold? In: Kirk SA (ed) Mental health in the social environment: critical perspectives. Columbia University Press, New York, 347-367

71. Kassirer JP (2005) On the take: how America's complicity with big business can endanger your health. Oxford University Press, Oxford and New York

72. Moynihan R, Cassels A (2005) Selling sickness: how the world's biggest pharmaceutical companies are turning us all into patients. Nation Books, New York

73. Smith R (2003) Medical journals and pharmaceutical companies: uneasy bedfellows. Br Med J 326:1202-1205

74. Mirowski P, Van Horn R (2005) The contract research organization and the commercialization of scientific research. Soc Stud Sci 35:503-548

75. Depressing research (2004) Lancet 363:1335

76. Giles J (2006) Stacking the deck. Nature 440

77. Quick J (2001) Maintaining the integrity of the clinical evidence base. Bull WHO 79:1093

78. De Angelis CD, Drazen JM, Frizelle FA et al (2005) Is this clinical trial fully registered? - a statement from the International Committee of Medical Journal Editors. New Engl J Med $352: 2436-2438$ 
79. Freedman R, Lewis DA, Michels R et al (2006) Conflict of interest, round 2. Am J Psychiatry 163:1481-1483

80. Cosgrove L, Krimsky S, Vijayaraghavan M et al (2006) Financial ties between DSM-IV panel members and the pharmaceutical industry. Psychother Psychosom 75:154-160

81. Fontanarosa PB, Rennie D, DeAngelis CD (2004) Postmarketing surveillance-lack of vigilance, lack of trust. JAMA 292 (21):2647-2650

82. Mathews AW (2004) Congress to discuss drug-label issues. Wall Street J Sept 8, p. B1

83. Judge: Paxil ads "misleading" (2002, August 21) CBS News. Retrieved April 15, 2004 from http://www.cbsnews.com/stories/ 2002/08/20/health/main519266.shtml

84. Schulman KA, Seils DM, Timbie JW et al (2002) A national survey of provisions in clinical-trial agreements between medical schools and industry sponsors. N Engl J Med 347(17):1335-1341

85. Harris G (2003) Debate resumes on the safety of depression's wonder drugs. New York Times. Aug 7, p. 1

86. Healy D (2006) Manufacturing consensus. Cult Med Psychiatry 30:135-156

87. Moynihan R (2004) Drug company targets US state health officials. BMJ 328:306

88. Barnett A (2003) Revealed: how drug firms 'hoodwink' medical journals. The Observer, Dec. 7. Retrieved Feb 72004 from http:// observer.guardian.co.uk/uk_news/story/ 0,6903,1101680,00.html

89. Fugh-Berman A (2006, April 15) The corporate author. J Gen Intern Med 20:546-548

90. Hearn K (2004) Here, kiddie, kiddie. Alternet. Retrieved Nov 29 2004 from http://www.alternet.org/story/20594

91. Healy D, Cattell D (2003) Interface between authorship, industry and science in the domain of therapeutics. Br J Psychiatry 183:22-27

92. Angell M (2000) Is academic medicine for sale? New Engl J Med 342:1516-1518
93. Wagner KD, Robb AS, Findling RI et al (2004) A randomized, placebo-controlled trial of citalopram for the treatment of major depression in children and adolescents. Am J Psychiatry 161:1079-1083

94. Meier B. (2004, June 21). A medical journal quandary: how to report on drug trials. New York Times, p. A-1

95. DeAngelis CD (2006) The influence of money on medical science. JAMA 296(8):996-998

96. Melander H, Ahlqvist-Rastad J, Meijer G et al (2003) Evidence b (i)ased medicine - selective reporting from studies sponsored by pharmaceutical industry: review of studies in new drug applications. Br Med J 326:1171-1175

97. Bennett CL, Nebeker JR, Lyons EA et al (2005) The Research on Adverse Drug Events and Reports (RADAR) project. JAMA 293(17):2131-2140

98. Lasser KE, Allen PD, Woolhandler SJ et al (2002) Timing of new black box warnings and withdrawals for prescription medication. JAMA 287(17):2215-2220

99. Egberts TC, Smulders M, de Koning FH et al (1996) Can adverse drug reactions be detected earlier? A comparison of reports by patients and professionals. BMJ 313(7056):530 531

100. Goozner M (2004) The $\$ 800$ million pill: the truth behind the cost of new drugs. University of California Press, Berkeley

101. Cohen D (2005) Doing away with prescription-only drugs. 23rd Annual Conference, National Association for Rights Protection and Advocacy, East Hartford, CT, 31 May

102. Summerfield A (1978) Behavioral toxicity: the psychology of pollution. J Biol Sci 10:335-345

103. King RA, Riddle MA, Chappell PB et al (1991) Emergence of self-destructive phenomena in children and adolescents during fluoxetine treatment. J Am Acad Child Adolesc Psychiatry 30: 179-186 